\title{
Conclusion: Legitimation and Accountability in Energy Transitions Research
}

\author{
Siddharth Sareen, Timothy Moss, Christian Lund, \\ Hàvard Haarstad, Benjamin Sovacool, and Steven Wolf
}

Abstract This concluding synthesis argues that practices of legitimation can empirically deconstruct any given energy transitions case to identify

S. Sareen $(\bowtie) \bullet$ H. Haarstad

Department of Geography, Centre for Climate and Energy Transformation, University of Bergen, Bergen, Norway

e-mail: Siddharth.Sareen@uib.no; Havard.Haarstad@uib.no

T. Moss

Integrative Research Institute on Transformations of Human-Environment Systems (IRI THESys), Humboldt University of Berlin, Berlin, Germany e-mail: timothy.moss@hu-berlin.de

C. Lund

Department of Food and Resource Economics, University of Copenhagen,

Copenhagen, Denmark

e-mail: clund@ifro.ku.dk

B. Sovacool

Science Policy Research Unit, University of Sussex, Falmer, UK

e-mail: b.sovacool@sussex.ac.uk

S. Wolf

Department of Natural Resources, Cornell University, Ithaca, NY, USA

e-mail: saw44@cornell.edu

(C) The Author(s) 2020

S. Sareen (ed.), Enabling Sustainable Energy Transitions, https://doi.org/10.1007/978-3-030-26891-6_10 
mechanisms that constrain or enable accountability to decarbonisation with social equity enhancement. The versatile analytical application of these practices can advance environmental governance research on steering energy transitions towards sustainability. This chapter explicates seven cross-cutting dimensions and indicates how practices of legitimation play out within them in five cases related to energy transitions, drawing on contextualised examples from two cases for each dimension. This illustrates how practices of legitimation (discursive, bureaucratic, technocratic and financial) can reframe wide-ranging cases from diverse perspectives, fields and disciplines. Applied researchers can choose customised dimensions and enlarge this indicative set to identify situated mechanisms that modulate accountable energy transitions.

Keywords Accountability • Governance $\bullet$ Legitimacy $\bullet$ Energy transitions $\bullet$ Sustainability

What is the collective takeaway from our exploratory analysis centred on accountability? Defined as accountability to decarbonisation with enhanced social equity, the concept is analytically generative for characterising components of any given energy transition as contributing to sustainability or not. Operationalised as four registers of practices of legitimation, accountability can be profitably applied across a wide range of cases. This application can emphasise specific cross-cutting dimensions based on which accountability relations are of contextual interest. The five cases highlight grounded practices of legitimation, whether discursive, bureaucratic, technocratic or financial, that relationally produce accountability. The dimensions that surface in these cases link accountability with other environmental governance concepts that are useful for advancing critical analyses of energy transitions. While provisional, this synthesis constitutes a basis that future research is invited to adapt and employ.

Section 10.1 furnishes a brief description of each of the seven indicative dimensions that are embodied in the five cases related to energy transitions in this book. Using illustrative examples from two cases for each of these dimensions, Sect. 10.2 demonstrates how practices of legitimation can be applied within each dimension. Finally, Sect. 10.3 summarises the 
significance of the five cases for future environmental governance scholarship on accountability in energy transitions.

\subsection{Accountability, Registers, Cross-cutting Dimensions and Practices of Legitimation}

Analyses focused on accountability relations can demonstrably construe a wide variety of cases in energy transition terms and pinpoint a range of accountability crises. Such reframing can help articulate how specific accountability crises are being maintained or challenged through practices of legitimation along registers of discourse, bureaucracy, technocracy and finance. This book has presented and consolidated a variety of case treatments-historical, conflict-centred, comparative, multi-scalar and crosssectoral. This foray has surfaced a number of cross-cutting dimensions. Sareen (2019a) argues in Chap. 9 that our case studies span and equip us to discern seven indicative dimensions that can serve to structure our insights and guide future application. Within each such dimension, it is possible to identify practices of legitimation that are at work to contest, uphold or produce new specific outcomes in relation to accountable energy transitions.

Table 10.1 plots the registers along which the practices of legitimation play out against each of the cross-cutting dimensions that come up due to case selection and approach, which are choices guided by analysts' contextual knowledge. This makes the practices of legitimation pliable and oriented at situated analyses of accountability. They can inform interdisciplinary analysis and identify interventions that can enable sustainable outcomes

Table 10.1 Practices of legitimation with indicative dimensions for five wideranging cases

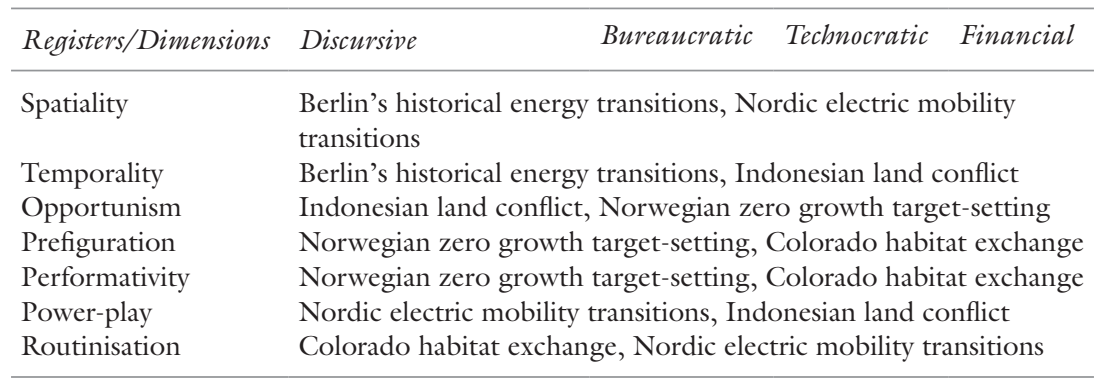


during energy transitions in a given context. The four registers along which legitimation is practised-discursive, bureaucratic, technocratic and financial - play out within each dimension represented in the rows. These dimensions include spatiality, temporality, opportunism, prefiguration, performativity, power-play and routinisation (or normalisation). The table indicates two main cases which concern each dimension, but aspects certainly surface in other cases as well. The dimensions structure our description of how practices of legitimation can be applied to analyse accountability in energy transitions governance. Despite the wide range of these five cases, future work along these lines will doubtless generate additional dimensions. Whereas the four registers along which legitimation is practised are elaborated in Chap. 2 (Sareen 2019b), the cross-cutting dimensions are explicated below with summary reflections on how each one manifests in two of the five cases.

\subsubsection{Spatiality}

Legitimation plays out simultaneously at and across multiple spatial scales during an energy transition. At stake are questions of distribution-where are benefits and burdens relocated from any sectoral changes, where are winners and losers based-and of the locus of decision-making and the sites that it affects across the spatial scale. In Berlin's historical energy transitions case, the spatial dimension appears pertaining to where energy is generated, where energy infrastructure is financed and where energy infrastructure is controlled and owned. This varies in relation to Berlin's territorial boundaries as well as the political economy of its geographical context. In the Nordic electric mobility transitions case, the spatial dimension relates to material decoupling in terms of where energy is produced to power the electric grid and where vehicles are manufactured. It also relates to where energy infrastructure like charging stations comes up, which jobs this creates and displaces, and what siting implies for which actors control electric mobility. Similar multi-scalar issues come up concerning material inputs (such as cobalt and lithium) as well as waste flows (especially electronic waste).

\subsubsection{Temporality}

Legitimation plays out differently over time, both during the same energy transition and during sequential ones. The temporal dimension directs 
attention to how sociotechnical and political economic configurations evolve within the same spatial context. This concentrates power at different spatial scales and makes different societal choices politically viable. It opens up new technological possibilities through arenas of innovation where timing and concomitant infrastructural investment dynamically determine energy futures. In Berlin's historical energy transitions case, these transitions are refracted by changing mores of political pressure interwoven with societal expectations and the material evolution of energy infrastructure. This includes the intergenerational equity aspects that underpin current campaigns to climate-proof Berlin's energy infrastructure. In the Indonesian land conflict case, citizens squeezed off their land by an authoritarian regime are forced to adopt new tactics to retain land control over time. This brings about new competing recognition of institutional authority by subjects. They seek to strengthen the state at the local scale where it is more responsive to their needs, creating new governmental configurations over time.

\subsubsection{Opportunism}

Legitimation plays out in powerful ways at specific conjunctures that can be definitive for a given energy transition. These moments of rupture or leverage points can be understood through the cross-cutting dimension of opportunism. Opportunistic or ad hoc legitimation capitalises on a circumstantial opening to wrest control of new possibilities and establish them in sociomaterial form through informal but rapidly formalised means rather than through existing formulae or behavioural patterns. It thus constitutes a quantum change in how society is configured with regard to a particular energy transition. In the Indonesian land conflict case, West Javanese villagers exercise their right to pay rent with discretion, recognising a local authority in the form of the Village Office rather than the central government. This in turn shapes relations of authority in favour of their recognition as landholders. In the Norwegian zero growth targetsetting case, a global $2{ }^{\circ} \mathrm{C}$ climate mitigation target is translated into a Zero Growth Objective to limit car traffic.

\subsubsection{Prefiguration}

Legitimation plays out in premeditated ways, where actors strategically manoeuvre energy transitions to secure advantageous new sectoral 
configurations. In contrast to opportunism, the dimension of prefiguration highlights how particular choices are orchestrated and made seemingly inevitable, despite having been initiated in a circumstance where they were highly contingent. This dimension enables us to trace how specific pathways are brought into being out of a wide array of possibilities. In the Norwegian zero growth target-setting case, setting a highly ambitious target that curbs any future increase in car traffic in Norway's largest cities puts a literal brake on this hitherto growing sectoral segment within a short span. In the Colorado case, the failed attempt to secure habitat replacement for the sage-grouse from land takeover by energy extractive industries nevertheless creates infrastructures for data (Habitat Quantification Tool) and markets (Colorado Habitat Exchange) for future habitat exchange.

\subsubsection{Performativity}

Legitimation plays out as farce that can risk perpetuating the status quo and supporting energy transitions that lead to unsustainable outcomes, for instance decarbonising without enhancing social equity. The dimension of performativity draws attention to this tendency of employing rhetoric to obfuscate the absence of sufficient substantive action. Legitimation can thus become a clever and attractive but ultimately hollow performance, where new accountability relations to transition in a sustainable manner are not shaped for a different energy future, despite fanfare. In the Norwegian zero growth target-setting case, the Zero Growth Objective can be read as an ambitious target that, without a slew of accompanying sectoral policies, would simply remain unattainable; more critically, it could be argued as a means of distracting attention away from the carbonemitting aviation sector which continues to grow. In the Colorado case, the expectation that a habitat exchange market would work (despite its subsequent failure) is implicated in the removal of compensatory mitigation mandates stemming from the Endangered Species Act.

\subsubsection{Power-play}

Legitimation plays out in uneven topographies of power, where outcomes are not shaped in a vacuum of fair decision-making processes, but socially modulated by influential actors within evolving institutional structures with specific historical legacies. The dimension of power-play highlights 
the role of both inequitable power relations and more structural factors such as path dependency and regime persistence during energy transitions. It directs attention not only to overt confrontation and contestation but also to the absence of important deliberations where power grabs or incumbency prematurely close particular energy futures. In the Nordic electric mobility transitions case, the automobility regime and existing biases of systems of mobility are reproduced in the roll-out of electric mobility to a greater extent than the adoption of public and non-motorised transport solutions. In the Indonesian land conflict case, West Javanese villagers are unable to even consider recourse to authority at the national scale for their marginalised concerns and resort to the local scale.

\subsubsection{Routinisation}

Legitimation plays out through enactment within the existing sociopolitical fabric, at times achieving incremental change with greater ease and effectiveness than through more disruptive attempts at energy transitions. Through routinisation or normalisation, practices of legitimation work their way into the bureaucratic and banal decision-making apparatus of existing, often powerful institutions. Rather than subjecting these institutions themselves to scrutiny, such legitimation reorients and repurposes their internal functioning. In the Colorado case, the choice of a habitat exchange is seen as a workable middle ground that can plausibly bring energy extractive industries on board in a politically feasible and efficient manner to replace sage-grouse habitats and conserve the declining population; Environmental Defense focuses its efforts not on protesting fossil fuels but on assembling requisite data and market infrastructure. In the Nordic electric mobility transitions case, while the roll-out of electric mobility might suffer from existing problems of mobility systems, policies to encourage and coordinate it have made the Nordic countries global front-runners in electric mobility adoption.

\subsection{Applying Practices of Legitimation Across Registers AND Dimensions}

Having defined the dimensions, the next section illustrates how the registers along which legitimation is practised can be applied within each dimension. We draw on the five cases whose practices of legitimation have 
been deconstructed and consolidated in Chap. 9 (Sareen 2019a). As illustrated above, multiple cases feature legitimation within each dimension; for clarity, we only present practices from two cases for each dimension.

\subsubsection{The Spatiality Dimension}

Within this dimension, discursive legitimation plays out at specific sites in situated ways, with consequences for what kind of energy transition is legitimated. In Berlin's historical energy transitions case, discursive legitimation appears spatially in the use of energy security arguments during the Cold War to push for self-sufficient energy production within city limit. It is also illustrated by the protest camp against the planned power plant in the Spandau Forest in 1976 (Fig. 4.2), which signifies contested territorialisation under energy transition. In the Nordic electric mobility transitions case, spatiality is implicit in people's critique of subsidies for luxury electric cars, which are equated with 30,000 transport tickets for each beneficiary, drawing attention to the spatial concentration of privilege and elitism, and its equity effects during transitioning mobility systems.

Bureaucratic legitimation is spatially expressed in the Berlin case as the municipal imposition of city-wide unitary tariffs across utilities and uniform service standards in the 1920s. This constitutes a smoothening and unification of urban territory for energy service delivery. Technocratic legitimation manifests spatially in the same case: the large incumbent utility Vattenfall's contemporary emphasis on technical expertise and track record for managing electricity and gas networks is a mode of ensuring continued relevance for actors with large spatial coverage, despite sectoral shifts towards openness to new small-scale actors. Financial legitimation also operates spatially in this case, as revealed in the adoption of city-wide fair and equal sectoral employee wages and service quality improvements to justify massive urban infrastructure investment (partly financed through foreign debt) in 1920s Berlin.

\subsubsection{The Temporality Dimension}

Here, discursive legitimation shows temporal significance in the Berlin case, pinpointed as discursive shifts from criticism of the regressive effects of tariff increases (by the local Communist Party during the 1920s) to a distinct emphasis on ownership in the campaign poster of the Berlin Energy Roundtable in 2013 (Fig. 4.3 shows this proclaiming 'Our 
municipal utility, our power grid, our Berlin' for a referendum). Priorities and their discursive justification change over time in ways that reveal an evolving basis for accountability claims. Bureaucratic legitimation also makes sense of temporal patterns such as in the Berlin case with high security standards built into the urban energy system in the 1970s, including three months' worth of primary energy reserves. This artefact of geopolitics has temporal legacies that shape subsequent energy infrastructure.

Technocratic legitimation exhibits a temporal dimension in the same case with Berlin's requirements for cascading generating capacity during the security-oriented strategy of the 1970s. These embed particular protocols into energy infrastructure that extend into current sectoral standards. In the Indonesian land conflict case, the transfer of nearly one million hectares of official forestland in West Java to the State Forest Corporation in 1978 centralises authority away from the province in a manner that gains significance during land ownership conflicts three decades later. Financial legitimation expresses temporally as a highlighted singularity in the Berlin case where, in contrast to urban politics shaping energy infrastructure investments, financing simply did not require validation at the urban scale during the Cold War years of prioritised energy security and West German government subsidies to Berlin.

\subsubsection{The Opportunism Dimension}

Within this dimension, discursive legitimation comes into play in the Indonesian land conflict case when the State Forest Corporation announces a planting ceremony of 1000 mahogany seedlings in rows named after government institutions, as well as when the villagers promptly uproot them overnight, both channelling the occasion into the purposive reframing of where authority rests, through imposition and resistance. Bureaucratic legitimation is notable within this dimension in the same case when the villagers request (and are granted) new ID cards from the Village Office as the local territorial administration, which renders their settlements official sub-villages in the territorial area claimed by the State Forest Corporation.

Technocratic legitimation exhibits an opportunistic dimension in the Norwegian zero growth target-setting case, when the National Transport Plan Working Group reasons that 'zero' is a very easy target to measure and thus useful in holding cities to account, and in subsequent agreements signed by Norway's largest cities with indicators to track performance on 
urban car traffic. Financial legitimation comes up in the Indonesian land conflict case by way of the provisory system of payment by villagers to the Sundanese Peasant's Movement, rather than paying rent illegally demanded by the State Forest Corporation. It is also present in each sub-village's annual contributions to the Village Office, in essence embodying a land tax to establish the villagers' claim as landholders.

\subsubsection{The Prefiguration Dimension}

Here, discursive legitimation is apparent in the Norwegian zero growth target-setting case, where the White Paper on Norwegian Climate Policy 2006 articulates the need for a shift to public and non-motorised transport, the White Paper on Norwegian Climate Policy 2012 formulates this as a 'goal' or target, and the Zero Growth Objective states that all growth in personal traffic in Norway's largest cities must come through public or non-motorised transport. Bureaucratic legitimation also takes on a prefigurative dimension in the same case, where Norway's policies (such as the Climate Accord of 2008) consistently reference a $2^{\circ} \mathrm{C}$ target to limit global warming and work this into a range of national documents and strategies, including for urban transport. This imbrication of a broad goal into concrete policies firms up the possibility of a stronger basis for ambitious energy transitions in urban mobility.

Technocratic legitimation is instantiated as prefigurative in the Colorado habitat exchange case in the innovation of the Habitat Quantification Tool, which can calculate compensation amounts for replacement of sagegrouse habitats. This paves the path for biodiversity conservation mechanisms in circumstances of greater political will. Financial legitimation is evidently prefigurative in the Norwegian target-setting case, where the Urban Environment Agreements under the Zero Growth Objective tie the central funding allocated to cities for local transport infrastructure with their prowess in meeting the target. This linkage moves future incentives for the sectoral evolution of urban mobility into closer alignment with accountability to sustainable energy transition targets.

\subsubsection{The Performativity Dimension}

Within this dimension, discursive legitimation is evident in the Colorado case, where the state habitat exchange was represented as relevant and vibrant despite never recording any transactions, and was used to argue 
against protecting the sage-grouse under a federal Endangered Species Act. The habitat exchange served as a mechanism to perform and uphold hollow accountability without changing substantive relations on the ground. Bureaucratic legitimation plays a performative role in the Norwegian case, where Norway's policies consistently reference a $2{ }^{\circ} \mathrm{C}$ target to limit global warming and have worked this into a range of national documents and strategies; this can also be seen as prefigurative in Sub-Sect. 10.2.4.

Technocratic legitimation is at work within the performative dimension in the Colorado case in terms of the strategy of championing a market mechanism to circumvent critique of coercive bureaucracy and benefit from efficiencies like low transaction costs. This strategy brings the Habitat Exchange and Habitat Quantification Tool into being. Financial legitimation is performative in the same case: questions of finance are used to delegitimate the whole exercise as the subject of controversy when the oil and gas industry protests the debits assigned to them based on the modelled cost calculations, as well as when it resigns from the governance board of the habitat exchange.

\subsubsection{The Power-play Dimension}

Here, discursive legitimation is in evidence in the Nordic electric mobility transition case. People's scepticism about hybrid vehicles surfaces in concerns that these allow their owners to cash in on incentives (for adopting low-emission vehicles) without affording the means to monitor their actual usage of electricity rather than the internal combustion engines. In the Indonesian land conflict case, the State Forest Corporation invokes military terms such as 'illegal loggers' and 'subversive' to draw equivalence between the villagers' land occupation and organised crime, another instance of power-play through discursive delegitimation. Bureaucratic legitimation operates as power-play in the Nordic case, when Norway offers all-inclusive incentive packages and Denmark maintains lower duties ( $40 \%$ instead of $150 \%$ ) for electric vehicles, but incentive schemes to electrify public transport remain far less substantial.

Technocratic legitimation manifests within the power-play dimension in the Indonesian land conflict case, where the State Forest Corporation uses the formal characterisation and protocols associated with national security to evict villagers as 'forest security disturbances'. This legitimation allows the state to levy its might against claim-making subjects. Financial 
legitimation embodies power-play in the Nordic electric mobility transitions case. Enormous support is provided for private electric cars used by relatively rich people, without similarly strong support to rapidly build out public electric transport infrastructure or cushion vulnerable groups against the regressive effects of fiscal policies on electric mobility.

\subsubsection{The Routinisation Dimension}

Within this dimension, discursive legitimation is in evidence in the Colorado habitat exchange case. The federal administration puts an end to mandatory compensatory mitigation by drawing explicit links with energy independence to make energy extraction an issue of national security. In the Nordic electric mobility transition case, protest against discursive legitimation to routinise inequitable transition surfaces as people's critique of political tokenism in public discourse around electric vehicles. Bureaucratic legitimation is expressed as routinisation in the Colorado case, where efforts by Environmental Defense, layered upon prior experiences with habitat offsets, orchestrate participation in the creation and governance of the Colorado Habitat Exchange by various relevant actors.

Technocratic legitimation appears as routinisation in the Nordic case, which identifies dynamics such as promoting off-peak charging, mandating battery recycling to reduce externalities, emphasising the decarbonisation of electric grids and coordinating electric vehicle roll-out with prioritised non-motorised and intermodal electric transport. Financial legitimation manifests as routinisation in the Colorado habitat exchange case. Finance remains absent in practice, but present in the very logic of markets as mechanisms for the efficient implementation of accountability on which the market-based offsetting of habitat loss is premised.

\subsection{Environmental Governance Research on Accountability in Energy Transitions}

Not all cases of energy transition necessarily feature practices of legitimation across all dimensions. The dimensions are partly an artefact of each author's strategically chosen focus and partly reflect data availability. Thinking in terms of accountability and legitimation does not supplant other methods and common sense, but rather offers diagnostic value. It is purposely pliable; the dimensions are overlapping, not mutually exclusive, 
nor comprehensive. Applied researchers and analytically oriented practitioners can apply the practices of legitimation to fit situated needs, mobilising the four registers within strategic dimensions of their choice. This analytical approach to accountability is based in abductive reasoning to settle upon the likeliest possible explanation in any given case of energy transition and pragmatically inform decision-making despite uncertainty. Such analysis can characterise disaggregated components of any energy transition case as accountable to concerns of sustainability or not. Scientifically evidencing both the formal and informal practices of legitimation that are at work during energy transitions can aid decision-making towards outcomes that decarbonise and enhance social equity. This approach can thus combine analytical rigour with practical applicability and real-world relevance.

The five cases in this book show that energy transitions are many things and involve not only changing energy sectors but also cognate sectors such as land, forest, transport, biodiversity, markets and political economies of multi-scalar contexts. Our practically oriented vision of enabling accountable governance for sustainable energy transitions represents a programmatic task across many sectors. To inform practical decision-making of various energy transitions and their constituent parts in contextually informed and responsive ways, applied researchers can operationalise an accountability-based approach in their respective fields within broader environmental governance scholarship. Their domain knowledge and disciplinary sensibilities will help them customise this approach to suit their purposes.

The illustrations in this book aim to aid such intellectual uptake and cross-fertilisation, and thus pave the path for situated efforts to study practices of legitimation. To demonstrate the generative potential of an accountability-based analytical approach to energy transitions governance, we offer closing reflections by working sequentially outward from the five cases.

In the Berlin case, Timothy Moss shows the relevance of historical accounts focused on accountability analysis to inform our understanding of energy transitions today by deconstructing assumptions along spatial and temporal axes. His overarching point is that histories of energy provision and use can be instructive sources of inspiration. The issue of accountability is not the preserve of present-day energy governance. It has been invoked in myriad ways in the past to justify energy solutions in certain places at certain times. History helps us understand accountability, 
therefore, as a situated political construct. This sensitises scholars not only to the variety of justifications that have been mobilised in the name of particular purposes and beneficiaries in the past but also to the ephemeral nature of accountability criteria. What today may seem self-explanatory, may tomorrow be questioned.

History can point us to times and places when crises of accountability did challenge prevalent logics, policies or practices of energy provision. Such critical junctures can reveal past attempts to delegitimate a hegemonic sociotechnical configuration and assess their achievements with the benefit of hindsight. At the same time, history can generate an appreciation of the obduracy of argumentative tropes enrolled to legitimate the predominant system. As the Berlin case illustrated, institutional norms can prove just as path dependent as the material structures they regulate. The fixation on energy security - and the capacity reserves this engendered-in West Berlin during the Cold War era created a legacy of insularity with which the city is still struggling to cope even 30 years after reunification.

Finally, history can direct attention to the roots of sustainability thinking in a particular space-time context. Sustainability as we know it was not a term in use before the 1970s, but its origins can be instructive, such as past efforts to save energy, use renewables or challenge supply-driven logics of supply. The social movements pioneering novel modes of accountable energy governance in Berlin today cannot be comprehended fully, Moss argues, without reference to their forebearers and the historically constructed sociotechnical regimes they challenged in bygone decades.

Christian Lund employs a conflict-centred approach anchored in a reading of classic texts within development studies, political science and political ecology to show how empirical examination of accountability is linked with the constitution of authority and subjecthood. Lund's (2016) overall argument is that to treat the 'state' (or any other institution) as a finished product gets in the way of understanding it. It is always in the making. Political authority is (re)produced through its successful exercise; especially when exercised over important issues in relation to the social actors concerned.

Arguably, when institutions recognise claims to rights, they themselves become recognised by the claimants of these rights. That is to say, rights and authority are mutually and simultaneously established. Claims therefore invoke public authority and governing capacity in different institutions, be they statutory or not. And, conversely, those who can claim to authorise people's claims to rights acquire and exercise political authority. 
This dynamic is garnered with attempts at legitimating the claims to rights and authority. However, just as the institutions are never truly settled but are, in fact, processes, the repertoires of legitimation are also contingent. To understand these dynamics of institutional formation requires grounded, empirical research allowing us to go beyond state theories modelled after ahistorical ideal types.

Lund's argument thus points to directions where fieldwork-based analyses of accountability can attend to indirect and under-attended aspects of energy transitions.

Håvard Haarstad brings a human geography and urban planning lens to bear on accountability along with a science and technology studies concern with metrics, revealing the relational modulation of energy transitions across multiple scales. His chapter deals with the question of whether climate targets matter for actual policy implementation. He observes that climate-related targets are all around-countries have them, regions have them, cities have them. Does this have any effects on how practical politics proceed, on what happens in practice? Much of the social sciences would take a sceptical view. Swyngedouw's (2010) popular rendering of the 'post-political condition', for example, describes climate targets as part of a techno-managerial apparatus that shifts rhetoric towards climate change but at the same time makes sure that nothing actually happens. While recognising the merits of a sceptical view, Haarstad aims to look at the other side of this coin. Is it possible that targets, even seemingly overly ambitious ones, may have real and substantive effects contributing to a sustainable transition?

He starts from the basic idea that there is power in numbers. As many social scientists have pointed out, quantification makes nature knowable and controllable (Miller 2005). This could mean that reducing a sustainable transition-a messy, complicated and multifaceted process-to a quantifiable target can have powerful effects. In fact, While et al. (2010) argue that, by lending itself to quantification, climate change becomes a potentially powerful target of political action and regulation. Haarstad points to one instance of how a quantified goal (zero) becomes enrolled and legitimated in political practice and, arguably, effects substantive change. Since 2006, the goal of having 'zero growth' in private car traffic has worked its way into Norwegian policy-making across a range of areas, particularly transport and urban development. It affects flows of funding from the national government to the major cities. It has become a major condition for urban policy-making. 
This illustrates how a quantified target has the potential to work its way into the 'techno-managerial apparatus' (Swyngedouw 2010) and inflect material change. This particular case entailed a combination of involved soft mechanisms, as the target gradually inserted itself in the discourse on urban policy and moved its goal posts, and hard mechanisms, namely national-to-urban funding flows. The takeaway message is that climaterelated targets can play an important role in legitimating practices that advance sustainable energy transitions.

Benjamin Sovacool demonstrates how a political economic, multi-sited comparative deconstruction of sectoral change from a public policy and social justice perspective can surface uneasy questions about accountability even in progressive energy transitions. Such an analysis offers a compelling antidote to the optimism inherent in much current discussion and debate about the desirability of electric mobility as a pathway for environmental sustainability. In this context, due to the transportation sector's dependence on fossil fuel energy sources and the monumental negative consequences for climate change, air pollution and other social impacts, countless researchers, policymakers and other stakeholders view a widespread transition to electric mobility as both feasible and socially desirable (Mitchell et al. 2010; Tran et al. 2012). The International Energy Agency (2017) projects under the 'Sustainable Development Scenario' that 875 million electric vehicles (EVs) will need to be adopted by 2040. Mitchell et al. (2010) call EVs nothing short of 'transformative' and 'revolutionary' for their potential effects on mobility patterns. Turton and Moura (2008, p. 1091) add that when EVs are placed in a vehicle-to-grid configuration, their transformative potential multiplies, representing 'a paradigm shift in how the energy and mobility markets are related'.

However, the Nordic transition to electric mobility when viewed from a framing of sector-wide multi-scalar linkages, questions this so-called revolution. It underscores how wedding accountability to analyses of vulnerability and justice in energy transitions can fruitfully change the frame and criteria by which we examine mobility transitions. In addition, many of the injustices identified, or the issues of equity and vulnerability that arise, are not 'new' to electric mobility-they likely exist with other low-carbon technologies and also conventional cars and other forms of mobility. However, a lesson here is perhaps that changing the performance or engine of a vehicle, or introducing a new type of car such as battery electric vehicle, does not necessarily change the underlying political economy or power dynamics behind mobility or automobility. Systems of mobility 
themselves-involving multiple, competing and overlapping technologies, modes of mobility and transport infrastructures-can also be just or unjust, even if they utilise innovations such as electric vehicles. The justice potential of electric mobility is therefore situational, relational and contingent.

Steven Wolf develops an environmental sociology framework to address dynamics in biodiversity conservation. The case of the sage-grouse, a ground-nesting bird imperilled by energy development in Colorado, USA, offers a window onto broader challenges of energy transitions and socioecological regulation. The chapter pursues a general, abstract analysis of accountability within environmental governance. Accountability mechanisms are identified as 'tests' of conformity with institutionalised norms. These tests mediate access to legitimacy and other resources that structure competition and organisational ecology dynamics (i.e., shifts in the population of actors and behaviours) (Kraft and Wolf 2018). The co-evolutionary model of socioecological regulation that is presented seeks to offer an integrated, dynamic treatment of accountability (e.g., social controls developed to regulate land use changes that reduce sage-grouse habitat), standards of legitimacy (e.g., prevailing norms regarding the appropriateness of accountability mechanisms), sociotechnical practices (e.g., oil and gas drilling activities) and environmental quality (e.g., health of sagegrouse populations). This theoretical treatment highlights opportunities for research on accountability to inform general analyses of governance and regulation.

The empirical analysis highlights how efforts to advance habitat offsetting (i.e., market-based approaches to conserving land in order to compensate for degradation of sage-grouse habitat) have served to maintain the legitimacy of existing models of oil and gas development. More specifically, Wolf's analysis highlights how multi-stakeholder dialogue around construction of habitat offsetting mechanisms and mobilisation of scientific expertise and quantification routines are implicated in performing conservation without producing measurable protections for sage-grouse. To date, after seven years of engagement, no habitat has been conserved in Colorado through the habitat exchange. Yet the public construction of elaborate new accountability routines and promises of future capacity to achieve 'no-net loss' of habitat seems to function adequately to legitimate existing socioecological relations. In this sense, accountability processes are a central mechanism through which we sustain the unsustainable (Blühdorn 2007). 
To conclude, we come full circle to the urgency of the climate change challenge, the need for sustainable energy transitions, and the conundrum that such sociotechnical transitions are feasible and desperately needed despite which they are held back in a wide variety of ways. The response unpacked by means of an accountability-centred analytical approach is that a dynamic configuration of legitimation practices that constrain and enable sustainable energy transitions manifest this conundrum. Identifying and evidencing these practices as applied researchers and analytically oriented practitioners, we can unravel the present conundrum and advance accountable governance for sustainable energy transitions. We trust that the pointers and reflections offered in this book will motivate and equip colleagues to support this endeavour.

\section{REFERENCES}

Blühdorn, I. (2007). Sustaining the unsustainable: Symbolic politics and the politics of simulation. Environmental Politics, 16, 251-275.

International Energy Agency. (2017). World energy outlook 2017. Paris: OECD.

Kraft, B., \& Wolf, S. (2018). Through the lens of accountability: Analyzing legitimacy in environmental governance. Organization \& Environment, 31, 70-92. https://doi.org/10.1177/1086026616680682

Lund, C. (2016). Rule and rupture. State formation through the production of property and citizenship. Development and Change, 47(6), 1199-1228.

Miller, C. (2005). New civic epistemologies of quantification: Making sense of indicators of local and global sustainability. Science, Technology and Human Values, 30, 403-432.

Mitchell, W. J., Borroni-Bird, C. E., \& Burns, L. D. (2010). Reinventing the automobile personal urban mobility for the 21st century. Cambridge, MA: MIT Press.

Sareen, S. (2019a). Practices of legitimation and accountability crises in a range of energy transitions. In Enabling sustainable energy transitions: Practices of legitimation and accountable governance. London: Palgrave Macmillan.

Sareen, S. (2019b). A typology of practices of legitimation to categorise accountability relations. In Enabling sustainable energy transitions: Practices of legitimation and accountable governance. London: Palgrave Macmillan.

Swyngedouw, E. (2010). Apocalypse forever? Post-political populism and the spectre of climate change. Theory, Culture \& Society, 27, 213-232.

Tran, M., Banister, D., Bishop, J. D. K., \& McCulloch, M. D. (2012). Realizing the electric-vehicle revolution. Nature Climate Change, 2, 328-333. 
Turton, H., \& Moura, F. (2008). Vehicle-to-grid systems for sustainable development: An integrated energy analysis. Technological Forecasting and Social Change, 75, 1091-1108.

While, A., Jonas, A., \& Gibbs, D. (2010). From sustainable development to carbon control: Eco-state restructuring and the politics of urban and regional development. Transactions of the Institute of British Geographers, 35, 76-93.

Open Access This chapter is licensed under the terms of the Creative Commons Attribution 4.0 International License (http://creativecommons.org/licenses/ by $/ 4.0 /$ ), which permits use, sharing, adaptation, distribution and reproduction in any medium or format, as long as you give appropriate credit to the original author(s) and the source, provide a link to the Creative Commons licence and indicate if changes were made.

The images or other third party material in this chapter are included in the chapter's Creative Commons licence, unless indicated otherwise in a credit line to the material. If material is not included in the chapter's Creative Commons licence and your intended use is not permitted by statutory regulation or exceeds the permitted use, you will need to obtain permission directly from the copyright holder.

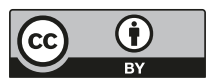

